\title{
The Analysis of B-cryptoxanthin and Zeaxanthin using HPLC in the Accumulation of Orange Color on Lowland Citrus
}

Inanpi Hidayati Sumiasih ${ }^{1,2}$, Roedhy Poerwanto ${ }^{1}$, Darda Efendi ${ }^{1,3}$, Andria Agusta $^{4}$ and Sri Yuliani ${ }^{5}$

${ }^{1}$ Agronomy and Horticulture Department, Faculty of Agriculture, Bogor Agricultural University, Bogor, Indonesia

${ }^{2}$ Agroecotechnology Program, Faculty of Bioindustry, Trilogi University, Jakarta, Indonesia

${ }^{3}$ Center for Tropical Horticulture Studies (PKHT) Baranangsiang Campus of IPB, Bogor, Indonesia

${ }^{4}$ Center for Biology, Indonesia Institute of Sciences (LIPI), Cibinong, Indonesia

${ }^{5}$ Center for Agricultural Postharvest Research and Development, Bogor, Indonesia

\section{Abstract}

Citrus peel color is one of the main quality attributes which was caused by the accumulation of carotenoids and its derivatives, especially 6 -citraurine. It makes citrus peel color looks attractive (orange). The orange color is a mixture of B-cryptoxanthin with b-citraurin. The objectives of this study were (1) to observe the effect of precooling and duration of proper ethylene exposure in the formation of orange color on citrus peel, (2) to identify and determine the 6 -cryptoxanthin content and total chlorophyll on citrus peel. Citrus was from Tuban, East Java while the study was conducted at PKHT IPB and LIPI. Precooling and without precooling treatment prior to injection of $100 \mathrm{ppm}$ of ethylene exposed at $15^{\circ} \mathrm{C}$, duration of exposure control (0), 24, and 48 hours. The results show that the best color of the Citrus Color Index $(\mathrm{CCl})$ is the precooling treatment and the duration of ethylene exposure for 24 hours, which can reduce total chlorophyll content about 8 times and proved to increase b-cryptoxanthin pigment content five times in accelerating the formation of orange citrus reticulata peel color to bright orange. Degreening has no significant effect on total dissolved solids and the firmness level of citrus fruits.

\section{Article History}

Received 23 November 2017

Accepted 21 December 2017

Keyword

B-cryptoxhantin

Citrus

Chlorophyll

Degreening

Ethylene zeaxanthin

\section{Introduction}

Peel color is one of external quality attributes of citrus and plays important factor in costumer decision in purchasing. Green-colored citrus is usually considered sour-tasted and unripe, while orange-colored citrus is considered otherwise. Generally, consumers choose orange-colored citrus. Therefore, it is essential to ensure that the citrus fulfills the criteria when it is ready to enter the market. 
In order to fulfill the consumers' demand regarding the taste, the accumulation of orange-colored on citrus peel through post-harvest treatment should be done. The treatment is degreening with ethylene. Degreening so far is still not succeed to form orange-colored citrus. In fact, it made the citrus to form yellow-colored peel. This result is also unfavorable because consumers consider yellow-colored citrus is in the verge of senescence.

Degreening in tropical region is still not success because $\beta$-citraurin pigment as the red color formation is not formed. Only yellow color pigment 6 -cryptoxanthin is formed. (Kato et al., 2006; Fanciullino et al., 2008). Yellow on citrus peel is caused by carotenoids derivative cryptoxanthin (Zhou et al., 2010). Orange color can be formed due to the mixture of 6 cryptoxanthin and B-citraurine (Stewart \& Wheaton, 1971; Rodrigo et al., 2013). While Bcryptoxanthin and zeaxanthin is the pigment contributed in the formation of 8 -citraurin (Ma et al., 2013).

The failure of degreening in Indonesia is because the citrus is not exposed to low temperature during its growth. Thus, $\mathbf{B}$-citraurin pigment can not be formed. It is only formed at $18-24{ }^{\circ} \mathrm{C}$. To substitute the existence of low temperature, the precooling treatment was introduced. Precooling after harvest is expected to substitute low temperature treatment which could not be fulfilled when the fruit is in the field. Ladaniya (2008) reported that low temperature affects greatly on the color changes on peel.

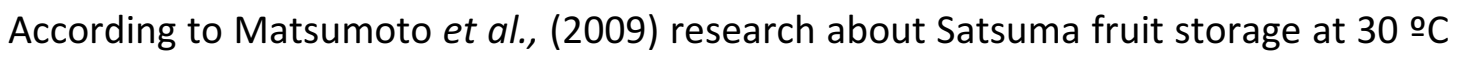
was proven to increase zeaxanthin and $b$-carotene but no 6 -citraurin pigment was found. The main reason of failure was that high temperature prevents the accumulation of $B$-citraurin and reduced orange color (Stewart \& Wheaton, 1971). High temperature on tropical regions limits the accumulation of important pigments on citrus and prevents its peel to achieve more favorable color.

Therefore, degreening technology which could induce citrus peel orange, reduce chlorophyll content, and identify b-cryptoxanthin as orange formation is needed. The research aims to observe the effect of precooling and obtain the proper ethylene exposure duration and to identify and determine 6-cryptoxanthin and Chlorophyll content on citrus peel before and after degreening.

\section{Materials and Methods}

The research was done at PKHT IPB and the analysis of chemical content of peel was done at LIPI Cibinong. It was conducted from January 2016 until July 2017. Materials used in the research were Citrus reticulate "Tejakula", ethylene gas, and liquid nitrogen. Tools used were degreening box, cool storage, syringe, refractometer, color reader, spectrophotometer, and chromatography, HPLC (High Performance Liquid Chromatography). A 2 factors Randomized Group Design was used as research design. Treatments were harvest and exposure duration. Harvest factor consists of 2 levels that is without precooling and precooling. Exposure duration factor consists of 3 levels, without ethylene exposure, exposure for 24 hours, and sxposure for 48 hours. There were 6 combinations repeated 3 times and 18 units of experiment.

Citrus reticulata "Tejakula" came from low land estate in Singgahan, Tuban, East Java (40 $\mathrm{m}$ asl). After the citrus was harvested and treated, it was brought to PKHT lab, Bogor. It was sorted and put into degreening box and sealed tightly (air tight). Ethylene gas 100 ppm was injected to the degreening box using $5 \mathrm{ml}$ syringe, then the citrus was put in cool storage at $15^{\circ} \mathrm{C}$. The fan was activated during degreening, which is control, 24 hours, and 48 hours. 


\section{Hue Angle and Citrus Color Indeks (CCI)}

Changes in the color quality of citrus peel was measured with Minolta Color Reader type 310 . This tool color notation system is hunter notation system (color system $L$, $a$, and b). The measurement results were expressed in the Citrus Color Index (CCl). Hunter color notation system is characterized by three parameters of color, the brightness symbolized by $L$, the chromatic colors symbolized by ' $a$ ' notation and color intensity with the notation ' $b$ '. Notation ' $L$ ' states the parameter of brightness (lightness), with value L: value 0 means black and 100 means white. While ' $a$ ' notation stating chromatic colors red-green mix with $+a$ (positive) from 0 to +100 indicating red color and value (negative) from 0 to -80 indicating green color, while the notation ' $b$ ' states chromatic color, the mixture of blue-yellow value $+b$ (positive) from 0 to +70 indicating yellow color and the $-b$ (negative) value from 0 to -70 indicating blue color (Andarwulan et al., 2011).

The value of Citrus Color Index (CCI) is a formula widely used to see the quality of citrus peel color. According to Jimenez-Cueata et al., (1981), Value Citrus Color Index (CCI) is a formula that is widely used to see the quality of orange peel color. Based on Jimenez-Cueata et al., (1981) that the value of $\mathrm{CCl}$ is used as followshe following equation:

$$
C C I=\frac{1000 \cdot a}{L \cdot b}
$$

Citrus Color Index (CCl) using following range: $\mathrm{CCl} \leq-5$ (dark green), $-5<\mathrm{CCl} \leq 0$ (green), $0<\mathrm{CCl} \leq 3$ (yellowish green), $3<\mathrm{CCl} \leq 6$ (greenish yellow), $6<\mathrm{CCl} \leq 8$ (yellowish orange), 8 $<\mathrm{CCl} \leq 10$ (orange), dan $\mathrm{CCl}>10$ (dark orange).

\section{Total Solluble Solid}

The fruit flesh of several samples from each treatment were taken and the total soluble solids was measured using a hand refractometer. A drop of juice was placed on hand refractometer prism.

\section{Fruit Firmness}

Fruit firmness is determined by fruit resistance to puncturing the peel done by penetrometer.

\section{Total Chlorophyll}

The total content of chlorophyll was measured using spectrophotometry method. Citrus peel was weighed at 0.5 grams and then crushed (slurry) and extracted with $2 \mathrm{~mL}$ acetris. The extract then inserted into microtube and centrifuged for 10 seconds. The centrifuged filtrate was inserted in a 1- $\mathrm{mL}$ reaction tube, and then $3 \mathrm{~mL}$ acetris was added and placed in cuvet to be measured using a spectrophotometer at wavelengths 537, 647 and $663 \mathrm{~nm}$. According to Sims and Gamon (2002), after obtaining an absorbance value, the total content of chlorophyll can be calculated by the following equation:

$$
\begin{gathered}
C h l_{a}=0.01373^{*} A_{663}-0.000897^{*} A_{537}-0.003046^{*} A_{647} \\
\text { Chl }_{b}=0.02405^{*} A_{647}-0.004305^{*} A_{537}-0.005507^{*} A_{663} \\
\text { Total Klorofil }=C \text { Chl } l_{a}+\text { Chl }
\end{gathered}
$$




\section{Identification of 6-cryptoxanthin and zeaxanthin Pigments}

\section{Material Preparation}

Citrus peels are separated from the edible portion, then immediately cooled with nitrogen liquid in the dewar tube until next step.

\section{Carotenoid Extraction}

The identification of carotenoids was performed by the method described by Kato et al (2004). The pigment was extracted from the sample with hexane solution: aceton: ethanol (2: $1: 1, \mathrm{v} / \mathrm{v}$ ) containing $0.1 \%(\mathrm{w} / \mathrm{v}) 2.6$ ditert butyl 4 methylphenol and $10 \%(\mathrm{w} / \mathrm{v})$ magnesium carbonate. After the organic solvent evaporates entirely, the carotenoidcontaining extract, which is esterified into fatty acid, is disacorated with $20 \%$ (w / v) methanolic $\mathrm{KOH}$. Water-soluble extracts are removed by saturated $\mathrm{NaCL}$. The pigments were partitioned in the dhietyl ether phase and evaporated.

\section{Analysis of B-cryptoxanthin, zeaxanthin and B-carotene}

The residue is redissolved in methyl tert butyl ether solution: methanol (4:6, v/v). An aliquot $(30 \mu \mathrm{L})$ is separated by an HPLC reversed phase (Shimadzu, Ascentis) equipped with

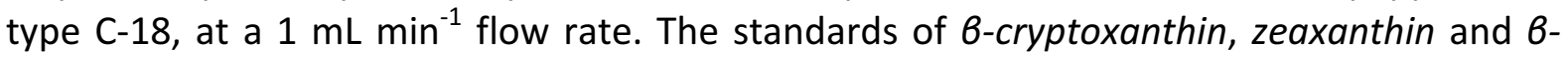
carotene were prepared based on the method described with fresh weight micrograms per gram (preparing for calibration of the standard). Quantification of B-cryptoxanthin, zeaxanthin and 6 -carotene was performed in 3 replications. The data were obtained from average HPLC values and calculated using the calibration equation. With standard pigments (Figure 1), and the calibration formula are as follows (Table 1):

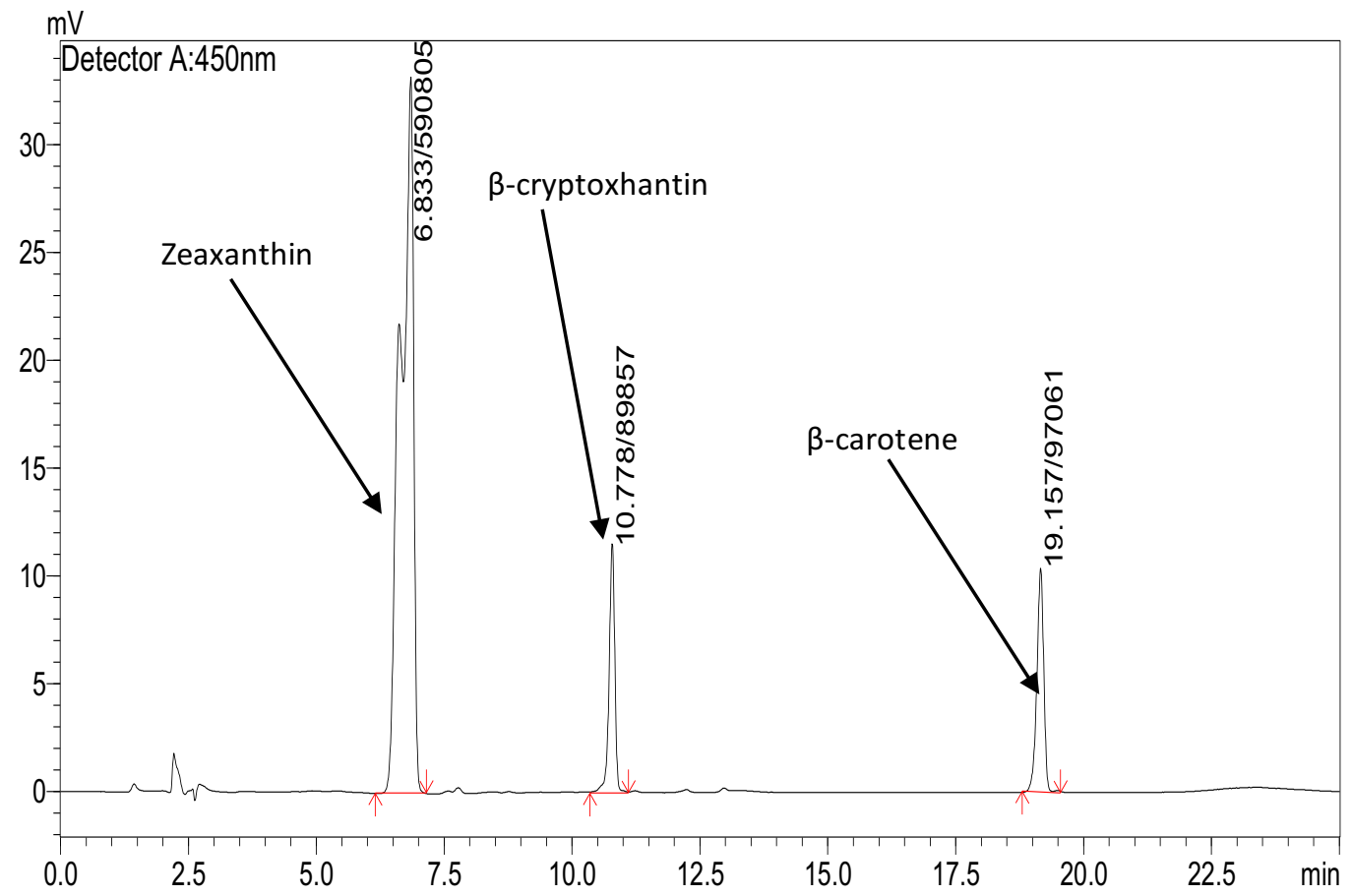

Figure 1. HPLC chromatogram for mixture of authentic sample of Zeaxhantin Bcryptoxanthin, and 6-carotene.

Table 1. The linier equation for 6 -carotene, $\beta$-cryptoxanthin, and zeaxanthin pigments 


\begin{tabular}{llll} 
& \multicolumn{1}{c}{ Zeaxantin } & \multicolumn{1}{c}{ Criptoxantin } & \multicolumn{1}{c}{ Caroten } \\
\hline Linier equation & $\mathrm{y}=86079 \mathrm{x}+44977$ & $\mathrm{y}=68174 \mathrm{x}+111876$ & $\mathrm{y}=3915.3 \mathrm{x}+249036$ \\
$\mathrm{R} 2$ & $\mathrm{R}^{2}=0.9938$ & $\mathrm{R}^{2}=0.9673$ & $\mathrm{R}^{2}=0.9838$ \\
\hline
\end{tabular}

Data Analysis

The results from observation were tested by using SAS software (Statistical Analysis System) The data were analyzed using Analysis of Variance at $5 \%$ significance level. When the result showed significant effect of the treatment, it will be tested further using Duncan Multiple Range Test (DMRT) at 5\% level.

\section{Results and discussion}

The effect of precooling and exposure duration to Citrus reticulata of Tuban origin showed the best color change was on the duration of 24 hours exposure with precooling and degreening treatment. Citrus peel color with precooling treatment on 24-hour ethylene exposure resulted in orange peel color, whereas without precooling showed a yellowish orange color (Figure 2, 3).

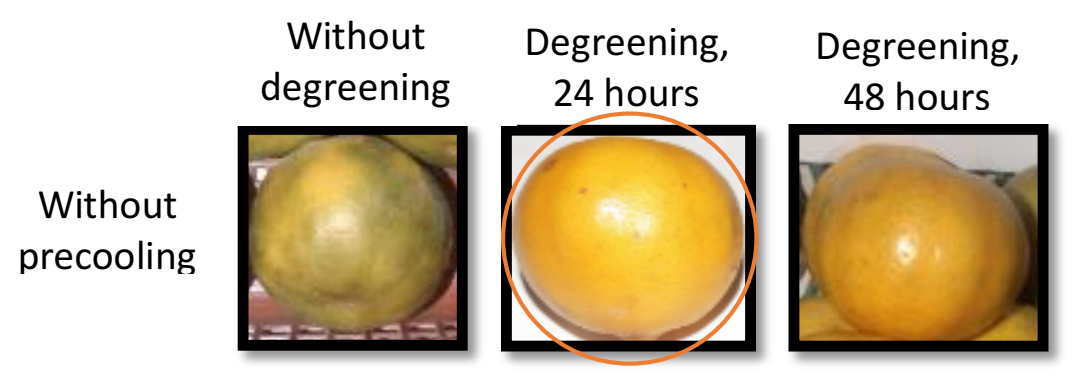

Figure 2. The change of Citrus reticulata 'tejakula' peel color without precooling treatment on several ethylene exposure durations ( 9 days after treatment)

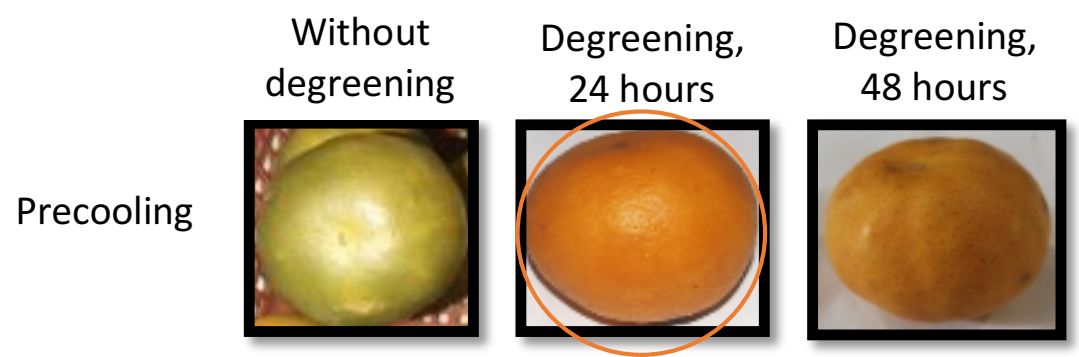

Figure 3. The change of Citrus reticulata 'tejakula' peel color with precooling treatment on several ethylene exposure durations ( 9 days after treatment)

Total soluble solids and and citrus firmness

The measurement for measuring citrus sweetness level is expressed in the content of total soluble solids. Based on the precooling treatment and ethylene exposure duration at the final observation, it was shown that the treatments gave no significant effects to total soluble solids and citrus firmness.

Table 2. The change of Citrus reticulata “tejakula' peel color with degreening treatment on several ethylene exposure durations $(0,12$ days after treatment)

Treatment Total soluble solids ( ${ }^{\circ}$ brix) Citrus firmness (Kgf)


$\begin{array}{llll}0 & 12 & 0 & 12\end{array}$

Day after treatment

\begin{tabular}{lllll}
\hline Precooling & & & & \\
- Non precooling & 10.76 & 10.76 & 0.58 & 0.62 \\
- Precooling & 10.77 & 10.72 & 0.56 & 0.62 \\
\hline Exposure durations & & & & \\
- O hour & 10.77 & 10.73 & 0.57 & 0.63 \\
- 2 h hours & 10.75 & 10.76 & 0.57 & 0.63 \\
- 48 hours & 10.79 & 10.74 & 0.57 & 0.60 \\
\hline
\end{tabular}

\section{Citrus Color Index Value (CCl)}

The use of the Citrus Color Index (CCl) value described colors such as red, orange or green. The increase of $\mathrm{CCl}$ value indicates that there is a change of color from green to orange. Precooling with degreening had an effect on the $\mathrm{CCl}$ value on Citrus reticulata to form orange color faster than treatment without precooling. The result of $\mathrm{CCl}$ measurements of Citrus reticulata with precooling treatment with degreening on 24-hour exposure duration, it could form orange color on day-9 after degreening with value 7.94. While the $\mathrm{CCl}$ value of Citrus reticulata given treatment without precooling on 24-hour exposure duration could form an orange color on day-12 of treatment with value 7.99 (data not shown).

\section{Total Chlorophyll}

The color variation of citrus fruits is caused by the main groups of chlorophyll pigments and carotenoids. The dominant pigment on unripe or ripe green fruit peel is chlorophyll (Rodrigo et al. 2013). The total chlorophyll of Citrus reticulata "tejakula" was observed at the time before degreening treatment (harvest, 0 days), without degreening ( 9 days after treatment) and precooling treatment with degreening ( 9 days after treatment). The total chlorophyll in Citrus reticulata "tejakula" with precooling and degreening treatment with 24 hours exposure decreased sharply with the lowest value compared to other treatments, with a value of $9.81 \mathrm{ug} \mathrm{g} \mathrm{FW}^{-1}$ on day-9 after treatment, initial chlorophyll content value before treatment $113.81 \mathrm{ug} \mathrm{g} \mathrm{FW}^{-1}$ (Figure 4).

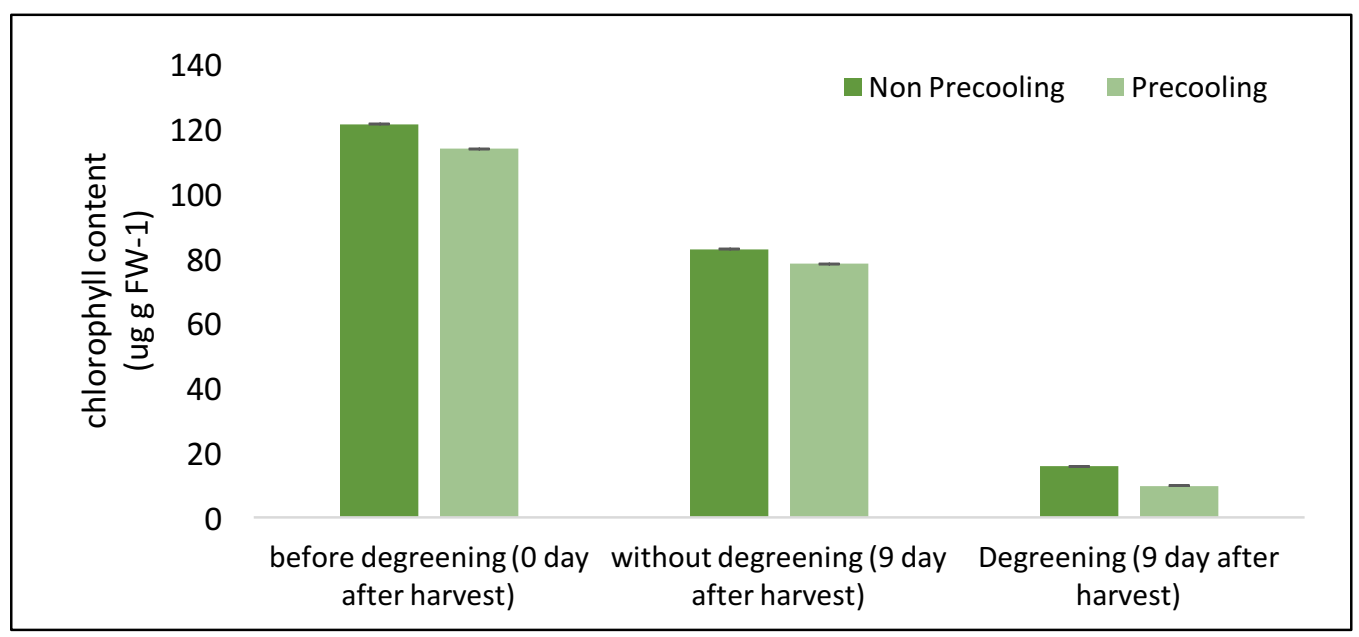

Figure 4. The change of total chlorophyll on citrus peel

Chlorophyll degradation causes color changes during degreening and the appearance of carotenoid pigment to produce orange color. These results are also similar to the study conducted by Stewart and Wheaton (1972); Rodrigo and Zacarias (2007) that ethylene 
applications triggered skin pigmentation by stimulating chlorophyll degradation and accumulation of carotenoids, including 6 -citraurin.

\section{Identification of $\beta$-Carotene, $\beta$-Criptoxanthin and Zeaxantin}

From the result, we can conclude that in order to form orange color on Citrus reticulata "Tejakula" in lowland, precooling prior to degreening is needed. Precooling and degreening treatments provided better and faster result in orange color accumulation. HPLC curve on zeaxanthin and $\beta$-cryptoxanthin pigments (Figure 5$)$. The content of $\beta$-cryptoxanthin on Citrus reticulata "Tejakula" with precooling and degreening treatments increased rapidly around 22.03 ug g FW-1 on day 9 after treatment (Figure 5).
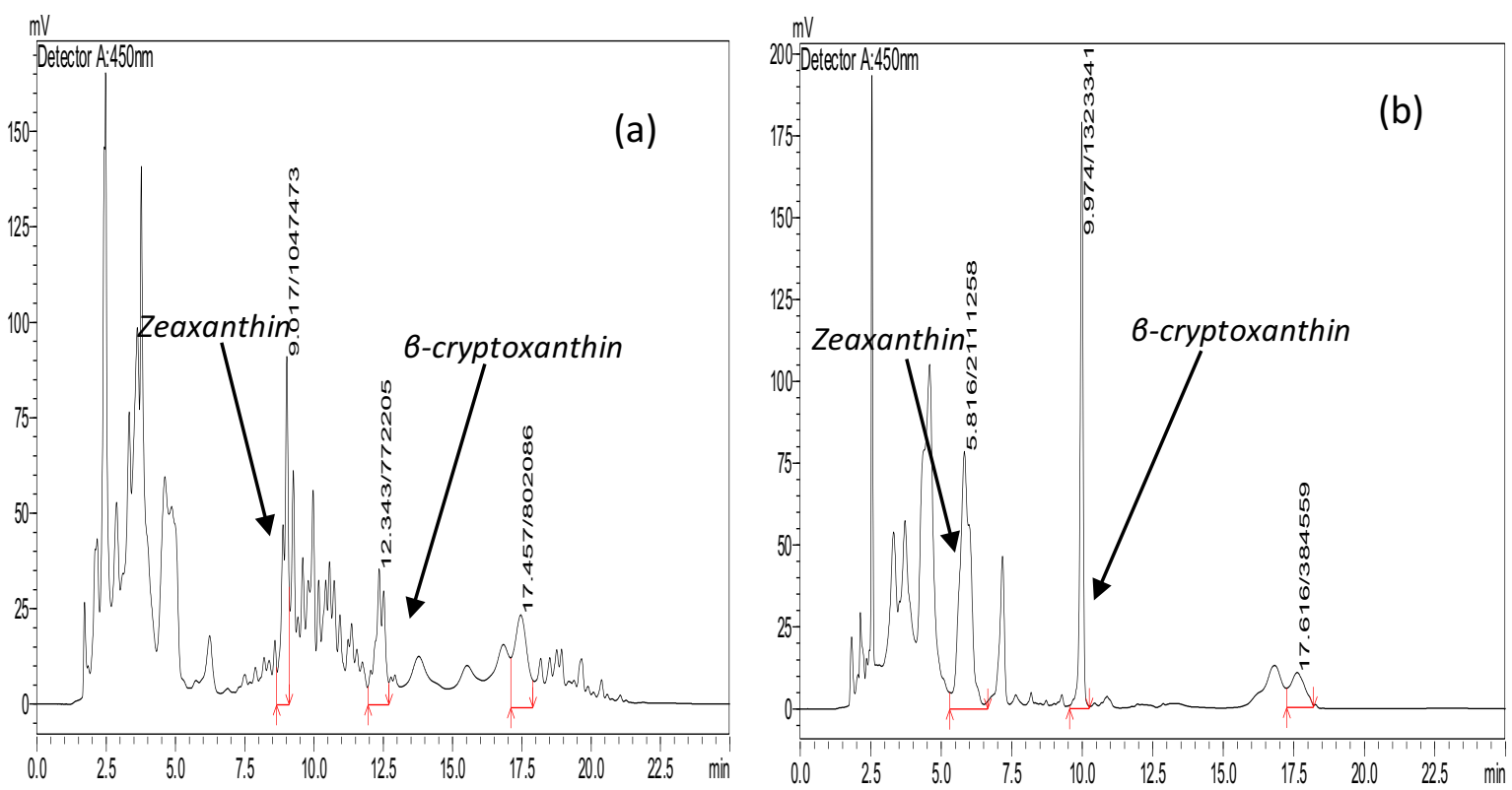

Figure 5. HPLC chromatogram of Citrus reticulata "Tejakula" without precooling (a), and precooling (b) (day 9 after treatment) with degreening

The content of zeaxhantin on precooling and degreening treatments and exposure duration for 24 hours resulted in 37.65 ug g FW-1 on day 9 after treatment. Zeaxhantin content without degreening shows lower value that is $12.22 \mathrm{ug} \mathrm{g} \mathrm{FW}-1$ (data not shown). This result is in accordance with Kato et al (2004); Rodrigo et al (2013) who stated that the change of citrus peel color from green to orange caused by nonphotosyntetic carotenoid synthesis, that is $\beta$-citraurin acts as the color formation to red-orange on Citrus nobilis peel. The accumulation of this compound is determined by precursor availability in carotenoids which is photosynthetic such as zeaxanthin, $\beta$-cryptoxanthin, karotenoid nonphotosintetic ( $\beta$ citraurin) which only take place in low temperature.

\section{Conclusions}

The Citrus Color Index $(\mathrm{CCl})$ is the precooling treatment and the duration of ethylene exposure for 24 hours, which can reduce total chlorophyll content about 8 times and proved to increase 6 -cryptoxanthin pigment content five times in accelerating the formation of orange Citrus reticulata peel color to bright orange. Degreening has no significant effect on total dissolved solids and the firmness level of citrus fruits. 


\section{Acknowledgment}

The author would like to express gratitude to Center for Tropical Horticulture Studies (PKHT) IPB and LIPI Cibinong which have facilitated the research. The author also would like to express gratitude to Ministry of Research, Technology, and Higher Education for the Doctoral Dissertation Research Grant with research contract number 0432/K3/KM/2017. The author also would like to thank to Ministry of Agriculture for the partnership grant which help funding the research with contract number 714/LB.620/1.1/2/2013.

\section{References}

Andarwulan, N., Kusnandar, F. \& Herawati, D. 2011. Analysis of Food. Jakarta. Dian Rakyat [In Indonesian]

Gang, Ma, Zhang L., Matsuta, A., Matsutani, K., Yamawaki, K., Yahata, M., Wahyudi, A., Motohashi, R. \& Kato M. 2013. Enzymatic Formation of $\beta$-Citraurin from b-Cryptoxanthin and Zeaxanthin by Carotenoid Cleavage Dioxygenase4 in the Flavedo of Citrus Fruit. American Society of Plant Biologists. 163(2):682-695.

Jiménez-Cuesta, M.J., Cuquerella, J. \& Martínez-Jávega, J.M. 1981. Determination of a Color Index for Citrus Fruit Degreening. In Proc. of the International Society of Citriculture. 2(5) : 750-753.

Kato, M., Ikoma, Y., Matsumoto, H., Sugiura, M., Hyodo, H. \& Yano, M. 2004. Accumulation of Carotenoids and Expression of Carotenoid Biosynthetic Genes during Maturation in Citrus Fruit. Biochemical Processes And Macromolecular Structures. 134(2) : 824-837.

Kato, M., Matsumoto, H., Ikoma, Y., Okuda, H \& Yano, M. 2006. The Role of Carotenoid Cleavage Dioxygenase in the Regulation Of Carotenoid Profiles During Maturation in Citrus Fruit. Journal of Exprimental Botany, 57(10):2153-2164.

Ladaniya, M.S 2008. Citrus Fruit. Biology, Technology and Evaluation. Principal Scientist (Horticulture). ICAR Research Complex for Goa : India.

Ministry of Agriculture. 2015. Prospect of Agricultural Commodities Subsector of Orange Horticulture. Jakarta: Agricultural Data and Information System Center of the Secretariat General - Indonesian Ministry of Agriculture [in Indonesian]

Rodrigo, M. J., Alquezar, M., Alos, E., Medina, V., Carmona, L., Bruno M. 2013. A Novel Carotenoid Cleavatage in the Biosynthesis of Citrus Fuit Specific Apocarotenoid Pigments. Experimental Botany, 64:4461-4478.

Rodrigo. M.J \& Zacarias, L. 2007. Effect of Postharvest Ethylene Treatment on Carotenoid Accumulation and the Expression of Carotetenoid Biosynthetic Genes in the Flavedo of Orange (Citrus cinensis L. Osbeck) Fruit. Scientia Hortikultura. 43:14-22

Sims, D.A., Gamon, J.A. 2002. Relationship between Leaf Pigment Content and Spectral Reflectance Across a Wide Range of Species, Leaf Structures and Development Stages. J Remote Sensing Envir. 81:337-354.

Stewart, I \& Wheaton, T.A. 1971. Effent of Ethylene and Temperature On Carorenoid Pigmentation of Citrus Pell. Proc. Fla. State hort. Soc, 84:264-266.

Stewart, I. Wheaton, T.A. 1972. Carotenoids in Citrus: their Accumulation Induced by Ethylene. J. Agric. Food Chem, 20:448-449.

Zhou, Y.J., Sun, C.D., Zhang, L.L., Dai, X., Xu, CJ \& Chen, K.S. 2010. Preferential Accumulation of Orange-Colored Carotenoids in Ponkan (Citrus reticulata) Fruit Peel Following Postharvest Application of Ethylene or Ethephon. J. Scientia Horticulturae, 126:229-235. 


\section{To cite this article:}

Sumiasih, I.H., Poerwanto, R., Efendi, D. \& Agusta, A. \& Yuliani, S. 2017. The Analysis of Bcryptoxanthin and Zeaxanthin using HPLC in the Accumulation of Orange Color on Lowland Citrus. International Journal of Applied Biology. 1(2): 37-45. 